University of Nebraska - Lincoln

DigitalCommons@University of Nebraska - Lincoln

USDA National Wildlife Research Center - Staff Publications
U.S. Department of Agriculture: Animal and Plant Health Inspection Service

February 2005

\title{
Attitudes of rural landowners toward wolves in northwestern Minnesota
}

Andreas S. Chavez

Utah State University, chavez.102@osu.edu

Eric M. Gese

Utah State University, eric.gese@usu.edu

Richard S. Krannich

Follow this and additional works at: https://digitalcommons.unl.edu/icwdm_usdanwrc

Part of the Environmental Sciences Commons

Chavez, Andreas S.; Gese, Eric M.; and Krannich, Richard S., "Attitudes of rural landowners toward wolves in northwestern Minnesota" (2005). USDA National Wildlife Research Center - Staff Publications. 506. https://digitalcommons.unl.edu/icwdm_usdanwrc/506

This Article is brought to you for free and open access by the U.S. Department of Agriculture: Animal and Plant Health Inspection Service at DigitalCommons@University of Nebraska - Lincoln. It has been accepted for inclusion in USDA National Wildlife Research Center - Staff Publications by an authorized administrator of DigitalCommons@University of Nebraska - Lincoln. 


\title{
Attitudes of rural landowners toward wolves in northwestern Minnesota
}

\author{
Andreas S. Chavez, Eric M. Gese, and Richard S. Krannich
}

\begin{abstract}
The natural recolonization of gray wolves (Canis lupus) into parts of their former range in the upper Midwest of the United States has led to wolves establishing territories in semiagricultural areas containing livestock. As part of a study on wolf-livestock relationships in a northwestern Minnesota agricultural area, we surveyed rural landowners within and outside of wolf range to assess perceptions regarding the risks wolves pose to livestock (mainly cattle). The mean response score for rural landowners to the statement "I think wolves should be allowed to exist in northwest Minnesota" was between neutral and disagree. There was no difference in mean response scores between rural residents living within wolf range and residents living adjacent to but outside of wolf range. The rural residents' mean response score to the statement "Wolves are causing unacceptable levels of damage to northwest Minnesota's livestock industry" was between neutral and agree. Although there was a statistical difference in mean response scores of residents living within wolf range and residents living outside of wolf range, the scores were not substantially different from each other. While landowners felt wolves were a threat to their livelihood, other factors (market fluctuations, laws and government, diseases, extreme weather, flooding) were ranked as greater threats to the agricultural community. Rural residents both within and outside of wolf range harbored similar negative attitudes toward wolves, even though residents outside of wolf range have not had a population of wolves in their area for $>100$ years, indicating little change in cultural attitudes toward wolves.
\end{abstract}

Key words attitudes, Canis lupus, livestock, northwest Minnesota, perceived risk, wolves

For centuries North Americans have held strong opinions regarding the place of gray wolves (Canis lupus) in society and the environment (Lopez 1978, Fritts et al. 2003). Stories vilifying wolves that originated in Europe were brought to North America and laid the foundation for negative sentiments toward wolves among EuroAmerican settlers (Fogleman 1988) and bolstered conflicts between wolves and livestock producers (Lopez 1978). As a consequence, humans began eradication campaigns against wolves throughout the contiguous United States (Klinghammer 1989, Fritts et al. 2003). These efforts (combined with habitat loss) decimated wolf populations in the contiguous United States and reduced wolf distribution to one remaining population in northeast Minnesota by the mid-twentieth century (Mech 2000, Fritts et al. 2003).

As attitudes toward wolves began to shift (Klinghammer 1989, Mech 1995, Fritts et al. 2003), strong antipathy toward these animals was replaced by an empathetic attitude for preserving them. In 1974 the United States Fish and Wildlife Service (USFWS) protected wolves in the contiguous United States under the Endangered Species Act. In 1978 the Eastern Timber Wolf Recovery Team proposed guidelines for recovering wolves in the upper Midwest (USFWS 1992).

\footnotetext{
Address for Andreas S. Chavez: Department of Forest, Range, and Wildlife Sciences, Utah State University, Logan, UT 84322, USA; present address: United States Fish and Wildlife Service, 6010 Hidden Valley Road, Carlsbad, CA 92009, USA. Address for Eric M. Gese: United States Department of Agriculture, Wildlife Services, National Wildlife Research Center, Department of Forest, Range, and Wildlife Sciences, Utah State University, Logan, UT 84322, USA; e-mail: egese@cc.usu.edu. Address for Richard S. Krannich: Department of Sociology, Social Work, and Anthropology, Utah State University, Logan, UT 84322, USA.
} 


\section{Wildlife Society Bulletin 2005, 33(2):517-527}

As wolves successfully reoccupied parts of Minnesota designated by the recovery team as "wolf zones" (Fritts and Mech 1981, Fuller et al. 1992), wolves began establishing territories in peripheral semi-agricultural areas (Berg and Benson 1999). Inevitably, wolf recovery led to increasing conflicts between wolves and livestock (Fritts and Mech 1981, Fritts 1982, Fritts et al. 1992, Mech 1998, Paul 1999).

Integrating public attitudes into the decisionmaking process is an expanding concern for many agencies involved in resource management. Attitudinal surveys of the public toward wolves range in scope from national to regional to park visitors (e.g., McNaught 1987, Bath 1991, Pate et al. 1996). Most of the general public is favorable toward wolves and wolf recovery, while farmers and ranchers hold the most negative attitudes (Kellert 1986, Nelson and Franson 1988, Bath and Buchanan 1989). With increasing conflicts between wolves and livestock in northwest Minnesota, attitudes of rural residents in the area may become important for wolf recovery (Mech 1995). Previous surveys found that rural residents in Minnesota who were most affected by wolves generally were the most negative toward them (Kellert 1986, 1999). Reasons behind their perceptions were complicated, with attitudes toward wolves influenced by proximate factors related to people's personal experiences and by deeply rooted factors such as cultural biases (Kellert 1986, Fritts et al. 2003).

As part of an ecological study examining wolf-livestock interactions in northwest Minnesota, we also wished to investigate the sociological aspects of this interaction. Our objectives were to assess rural residents' attitudes toward wolves in northwest Minnesota and determine the degree to which proximate factors related to personal experience influenced attitudes and perceptions of the risk wolves pose to livestock and the agricultural community. The main factors we examined were geographic proximity to wolf range and occupation. We hypothesized that residents living within wolf range would show greater personal experience with and concern about conflicts associated with wolves and therefore be less accepting of the risk wolves pose to livestock (e.g., Vaughan 1990) than residents living outside of wolf range. In addition, we hypothesized that residents raising livestock may be less accepting of wolves than residents not raising livestock.

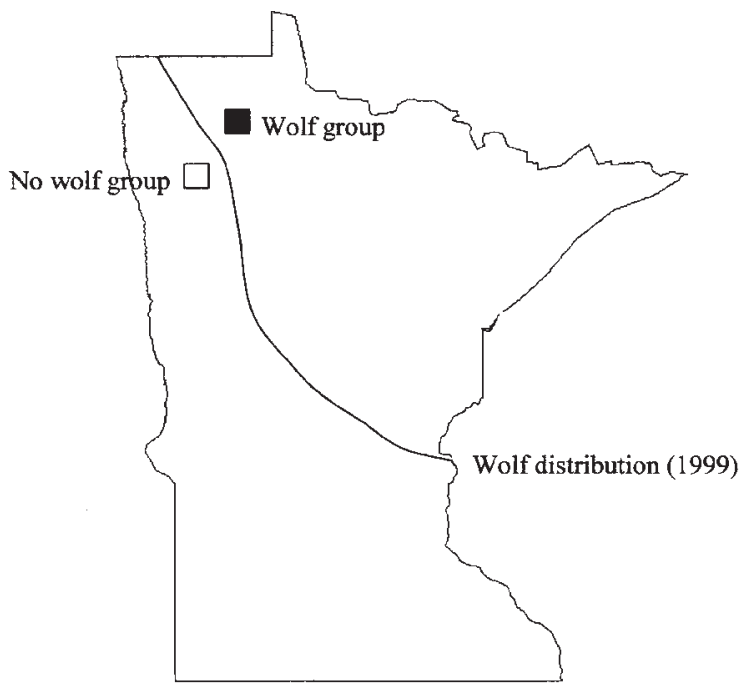

Figure 1. Location of "wolf group" and "no wolf group" sample populations relative to wolf distribution in Minnesota during 1999 (wolf range boundary from Ream 2000).

\section{Methods}

In 1999 the boundary of wolf range in the upper Midwest divided northwest Minnesota into a "no wolf area" and a "wolf area" (Figure 1; Berg and Benson 1999, Mech 2000, Ream 2000). In October-November 1999, we surveyed 600 rural residents from 2 groups: 300 living within wolf range ("wolf group") and 300 in an area adjacent to but outside of wolf range ("no wolf group"). We determined sample size for both surveyed populations by the maximum number of rural residents living $<8 \mathrm{~km}$ from the boundary of Agassiz National Wildlife Refuge (NWR), located in a semi-agricultural area with a concurrent study on wolf-livestock interactions (Chavez 2002) within the boundary of wolf distribution (Ream 2000). We chose the second sample population due to similar environmental, social, and agricultural characteristics and its relatively close proximity $(<97 \mathrm{~km})$ to the first population. The "wolf group" consisted of residents in a part of Marshall County, while the "no wolf group" consisted of residents in parts of Pennington and Red Lake Counties (Figure 1). We delivered questionnaires only to residents with rural addresses; we deliberately excluded residents with city or town addresses. We randomly drew names and addresses of rural residents from county plat books.

To assist in survey design, we first implemented a semi-structured interview protocol to collect information regarding rural residents' perceptions 
of wolves around the Agassiz NWR area. The interview targeted 11 landowners living near Agassiz NWR who were considered "key informants." The purpose of targeting "key informants" was to take advantage of their knowledge and insights about others in their community and the dynamics of their social context. We completed each interview in one 45-minute session. We organized interviews in a semi-structured manner with open-ended questions. We assembled topics, themes, and issues into the protocol to guide the interview but also allowed expansion of ideas by the informant. These interviews provided qualitative information on attitudes and opinions toward wolves that prevailed in these rural community settings. We used these insights to help formulate the structured survey questionnaire.

The structured survey consisted of 26 statements and questions covering attitudes toward wolves in northwest Minnesota, perceived level of threat wolves pose to agricultural interests, and knowledge about the status of the wolf in Minnesota. In addition, we measured respondent demographic characteristics including involvement in livestock production. We posed attitudinal statements as closed-ended statements with ordered answer choices. Most statements adhered to 1 of 25 -point Likert formats: $[1]=$ strongly disagree, $[2]=$ disagree, $[3]=$ neutral, $[4]=$ agree, $[5]=$ strongly agree; or $[1]=$ no threat, $[2]=$ small threat, $[3]=$ moderate threat, $[4]=$ large threat, $[5]=$ very large threat. Questionnaire design procedures followed guidelines of Dillman (1978). We distributed questionnaires in the "wolf group" using a drop-off-mailback method because the appearance of a research worker-whether delivering the questionnaire, picking it up, or both-has been shown to result in higher completion rates than standard mail surveys (Babbie 1990). In contrast, due to time and budget constraints, we used a mail survey method for the "no wolf group." Each questionnaire package included a cover letter explaining the purpose of the survey and participating groups, a 7-page questionnaire, and a self-addressed stamped envelope. We requested that the adult member of the household most recently celebrating his or her birthday be the individual to fill out the questionnaire, to reduce potential for gender bias among respondents. We conducted two follow-up phone calls to nonrespondents at 2 and 4 weeks after initial delivery of questionnaires. We sent replacement questionnaires to nonrespondents requesting them.
The overall completion rate was $55 \%$, with $58 \%$ in the "wolf group" and 51\% in the "no wolf group." Because this was below our desired completion rate of $75 \%$, we tested for nonresponse bias. We conducted the nonresponse bias test with follow-up phone calls to a random sample of 25 nonrespondents from each group. We asked only 2 key attitudinal statements from the questionnaire to minimize the length of each phone call: 1) "I think wolves should be allowed to exist in northwest Minnesota", and 2) "Wolves are causing unacceptable levels of damage to northwest Minnesota's livestock industry." We also asked 5 key demographic questions for the nonresponse bias test: respondent's sex, place of residence, involvement in agriculture, involvement in livestock production, and involvement in preventing damage caused by wolves.

Data were analyzed using SPSS (SPSS 1998). We used a two-sample $t$-test to compare mean scale scores for each geographic and occupational group. In addition, we compared statements and questions with a chi-square statistic to determine relationships between geographic and occupational groups, level of agreement toward the existence of wolves, and level of risk wolves pose to livestock. If relationships were significant with the chi-square test, we used a measure of association for ordinal scales ( $\left.\operatorname{tau}_{c}\left[\tau_{c}\right]\right)$ to measure strength of relationships between variables. To test for nonresponse biases, we used a twosample $t$-test to compare mean scale scores between respondents and nonrespondents. All results were assumed significant at $P<0.05$. Furthermore, we also examined the data for substantive differences; we considered differences between mean scale scores substantive if $>1$ point apart.

\section{Results}

The majority of respondents in both groups were male with a mean age $>50$ years (Table 1 ). Nearly all respondents for both groups claimed rural areas as their current place of residence and their place of residence while growing up. Most respondents in both groups were currently involved in agricultural production, with about half of them raising livestock. More respondents from the "wolf group" than the "no wolf group" stated they or their immediate family members had personally experienced wolf depredations on livestock $\left(\chi^{2}=16.78, \mathrm{df}=1\right.$, $P<0.05)$. Within the "wolf group", a higher proportion of livestock producers $(71 \%)$ than nonlivestock producers $(50 \%)$ said they or their immediate 
Table 1. Demographic information for respondents from the "wolf group" and "no wolf group" surveyed in northwestern Minnesota, 1999.

\begin{tabular}{lcc}
\hline & \multicolumn{2}{c}{ Geographic area } \\
\cline { 2 - 3 } & Wolf group & No wolf group \\
\hline Sex ratio $(\mathrm{M}: \mathrm{F})$ & $81: 19$ & $76: 24$ \\
Mean age $( \pm \mathrm{SD})$ & $57 \pm 15$ & $53 \pm 14$ \\
$\%$ current rural residents & 98 & 98 \\
$\%$ rural residents in the past & 91 & 91 \\
$\%$ involved in agriculture production & 74 & 65 \\
$\%$ involved in raising livestock & 48 & 50 \\
$\%$ experienced wolf depredations & 56 & 32 \\
$n$ & 174 & 153 \\
\hline
\end{tabular}

Within the "wolf group", the mean score among livestock producers $(\bar{x}=$ $2.53 \pm 1.20, n=74) \mathrm{did}$ not differ from nonlivestock producers $(\bar{x}=2.62$ $\pm 1.24, n=78 ; t=0.447, \mathrm{df}$ $=151, P=0.656$ ). In addition, cross tabulation revealed no relationship between occupation type and level of agreement with the statement $\left(\chi^{2}=\right.$ $1.29, \mathrm{df}=4, P=0.863$ ).

family members had personally experienced wolf depredations on livestock $\left(\chi^{2}=6.50, \mathrm{df}=1, P<\right.$ $0.05)$. Within the "no wolf group", we found no difference between the livestock (42\%) and nonlivestock-producer groups (29\%) stating they or their immediate family members had personally experienced wolf depredations on livestock $\left(\chi^{2}=2.065\right.$, df $=1, P=0.151)$. Among livestock producers in the "wolf group", $37 \%$ practiced some method of protecting livestock, with "moving livestock away from wolves" the most common method (Figure 2).

During the nonrespondents' bias check, males were overrepresented in the survey for both the "wolf group" $\left(\chi^{2}=19.811, \mathrm{df}=1, P<0.001\right)$ and "no wolf group" $\left(\chi^{2}=8.304, \mathrm{df}=1, P=0.004\right)$, despite instructions that should have produced an unbiased gender representation among respondents. We found no nonresponse biases for any other demographic variables in either group. We found no differences between respondents and nonrespondents within the "wolf group" regarding the 2 attitudinal statements (Student $t$-test, all $P$-values $>0.05$ ). However, nonrespondents within the "no wolf group" expressed stronger agreement than respondents to the statement "wolves should be allowed to exist in northwest Minnesota" ( $t=$ $-2.156, \mathrm{df}=170, P=0.033$; Table 2).

\section{Attitudes on whether wolves should be allowed to exist in northwest Minnesota}

When asked whether wolves should be allowed to exist in northwest Minnesota, mean score for respondents in the "wolf group" $(\bar{x}=2.61 \pm 1.23, n$ $=171)$ did not differ from the "no wolf group" $(\overline{\mathrm{x}}=$ $2.67 \pm 1.21, n=147 ; t=0.431, \mathrm{df}=317, P=0.667$ ). Cross tabulation did not reveal a relationship between geographic group and levels of agreement with the statement $\left(\chi^{2}=1.21\right.$, df $\left.=4, P=0.876\right)$. agreed or strongly agreed; similarly $28 \%$ of the nonlivestock producer group agreed or strongly agreed. Within the "no wolf group", the level of agreement between livestock producers $(\bar{x}=2.45 \pm$ $1.24, n=62)$ and nonlivestock producers $(\bar{x}=2.77$ $\pm 1.20, n=61)$ did not differ $(t=1.449, \mathrm{df}=122, P$ $=0.150$ ) in regard to whether "wolves should be allowed to exist in northwestern Minnesota", and we found no relationship between occupation type and level of agreement $\left(\chi^{2}=2.87, \mathrm{df}=4, P=\right.$ 0.580). Among livestock producers, $21.0 \%$ of respondents agreed or strongly agreed, while $29.6 \%$ of the nonlivestock group agreed or strongly agreed.

\section{Attitudes about whether wolves should be allowed to exist in northwest Minnesota if they do not disturb livestock often}

Regarding the statement "Wolves should be allowed to exist in northwestern Minnesota if they didn't disturb livestock often", respondents in the

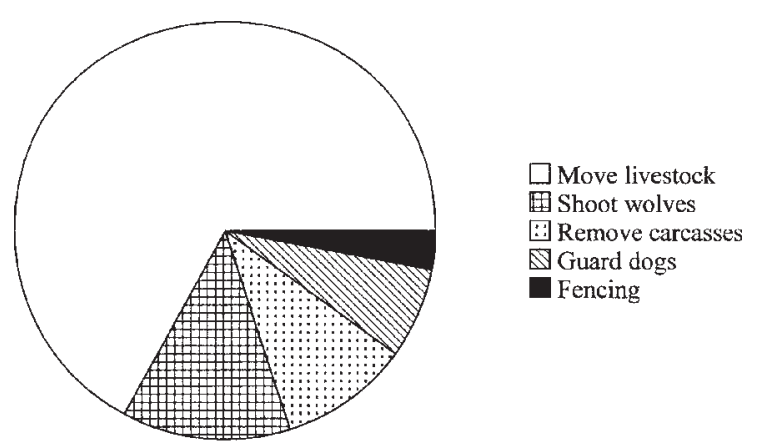

Figure 2. Methods (\%) used by livestock producers to protect their livestock from predation by wolves, northwest Minnesota, 1999.
Among livestock producers, $27 \%$ of respondents 
Table 2. Mean Likert response score $(1=$ strongly disagree, $5=$ strongly agree $)$ to attitudinal questions between respondents and nonrespondents, northwestern Minnesota, 1999.

\begin{tabular}{|c|c|c|c|c|}
\hline & \multicolumn{2}{|c|}{ Respondents } & \multicolumn{2}{|c|}{ Nonrespondents } \\
\hline & $\bar{x}$ & (SD) & $\bar{x}$ & (SD) \\
\hline \multicolumn{5}{|c|}{$\begin{array}{l}\text { A. Wolves should be allowed to exist in } \\
\text { northwestern Minnesota }\end{array}$} \\
\hline Within wolf range & 2.61 & $(1.23)$ & 2.84 & $(1.28)$ \\
\hline Outside wolf range & 2.67 & $(1.22)$ & 3.24 & $(1.20)$ \\
\hline \multicolumn{5}{|c|}{$\begin{array}{l}\text { B. Wolves are causing unacceptable levels } \\
\text { of damage to northwest Minnesota's } \\
\text { livestock industry }\end{array}$} \\
\hline Within wolf range & 3.78 & $(1.15)$ & 4.08 & $(0.97)$ \\
\hline Outside wolf range & 3.48 & $(1.03)$ & 3.36 & $(1.00)$ \\
\hline
\end{tabular}

$P=0.95)$. Among livestock producers, $40.9 \%$ of respondents agreed or strongly agreed with the statement while $48.2 \%$ of the nonlivestock producers agreed or strongly agreed.

\section{Perceptions on} whether wolves are causing unacceptable levels of damage

When asked whether "wolves were causing

"wolf group" ( $\bar{x}=2.85 \pm 1.37, n=166)$ did not differ from the "no wolf group" $(\bar{x}=2.94 \pm 1.32, n=$ $140 ; t=0.56, \mathrm{df}=305, P=0.58)$. In both areas the mean score was near neutral, with an almost equal split between the respondents who agreed or disagreed. Within the "wolf group", 48.2\% disagreed or strongly disagreed with the statement whereas $43.9 \%$ of the respondents agreed or strongly agreed. Within the "no wolf group", $42.2 \%$ of the respondents disagreed or strongly disagreed, while $44.3 \%$ of the respondents agreed or strongly agreed. Cross tabulation revealed no relationship between geographic group and level of agreement $\left(\chi^{2}=3.10, \mathrm{df}=4, P=0.54\right)$.

Respondents in both occupation types in the "wolf group" were split in terms of disagreeing or agreeing with the statement "Wolves should be allowed to exist in northwestern Minnesota if they don't disturb livestock often", with livestock producers $(\bar{x}=2.56 \pm 1.28, n=73)$ close to but not different from nonlivestock producers $(\bar{x}=3.00 \pm$ $1.45, n=77 ; t=1.96$, df $=149, P=0.052$ ). Cross tabulation did not reveal a relationship between occupation type and level of agreement with the statement $\left(\chi^{2}=7.17\right.$, df $\left.=4, P=0.13\right)$. Among livestock producers $35.6 \%$ of the respondents agreed or strongly agreed with the statement while $49.4 \%$ of the nonlivestock producers agreed or strongly agreed. Within the "no wolf group", mean score among livestock producers $(\bar{x}=2.87 \pm 1.32, n=61)$ to the statement that "wolves should be allowed to exist in northwestern Minnesota if they don't disturb livestock often" was not different from nonlivestock producers $(\bar{x}=3.05 \pm 1.34, n=56 ; t=$ 0.75 , df $=117, P=0.46)$. Cross tabulation revealed no relationship between occupation type and level of agreement with the statement $\left(\chi^{2}=0.75, \mathrm{df}=4\right.$, unacceptable levels of damage to northwest Minnesota's livestock industry", respondents in the "wolf group" $(\bar{x}=3.78 \pm 1.15, n=166)$ agreed slightly more strongly than respondents in the "no wolf group" $(\bar{x}=3.48 \pm 1.03, n=141 ; t=2.40, \mathrm{df}=$ $305, P=0.017)$. Similarly, cross tabulation revealed a relationship between geographic group and level of agreement with the statement $\left(\chi^{2}=16.80, \mathrm{df}=\right.$ $\left.4, P<0.05, \tau_{\mathrm{c}}=0.194\right)$. We found $71.1 \%$ of respondents in the "wolf group" agreed or strongly agreed with the statement compared to $56.8 \%$ of respondents in the "no wolf group" agreed or strongly agreed (Figure $3 a$ ). Within the "wolf group", livestock producers $(\bar{x}=3.97 \pm 1.07, n=71)$ did not differ from nonlivestock producers $(\bar{x}=3.76 \pm$ $1.03, n=78 ; t=1.17$, df $=147, P=0.243$ ), and cross tabulation revealed no relationship between occupation type and the level of agreement $\left(\chi^{2}=3.88\right.$, df $=4, P=0.42)$. A majority of livestock and nonlivestock producers agreed or strongly agreed with the statement (Figure 3b). Similarly, within the "no wolf group", the mean score among livestock producers $(\bar{x}=3.59 \pm 1.07, n=59)$ did not differ from nonlivestock producers $(\overline{\mathrm{x}}=3.50 \pm 0.96, n=58 ; t=$ 0.496 , df $=115, P=0.621$ ), and we found no relationship between occupation type and the level of agreement with the statement $\left(\chi^{2}=2.17, \mathrm{df}=4, P\right.$ $=0.71)$. A majority of the livestock and nonlivestock producers agreed or strongly agreed with the statement (Figure 3c).

\section{Perceptions of the risk that wolves pose to farming in nortbwestern Minnesota}

Respondents in the "wolf group" perceived that wolves were a moderate to large threat to farming in northwest Minnesota $(\bar{x}=3.58 \pm 1.03, n=170)$, which was higher than the "no wolf group" $(\bar{x}=$ 

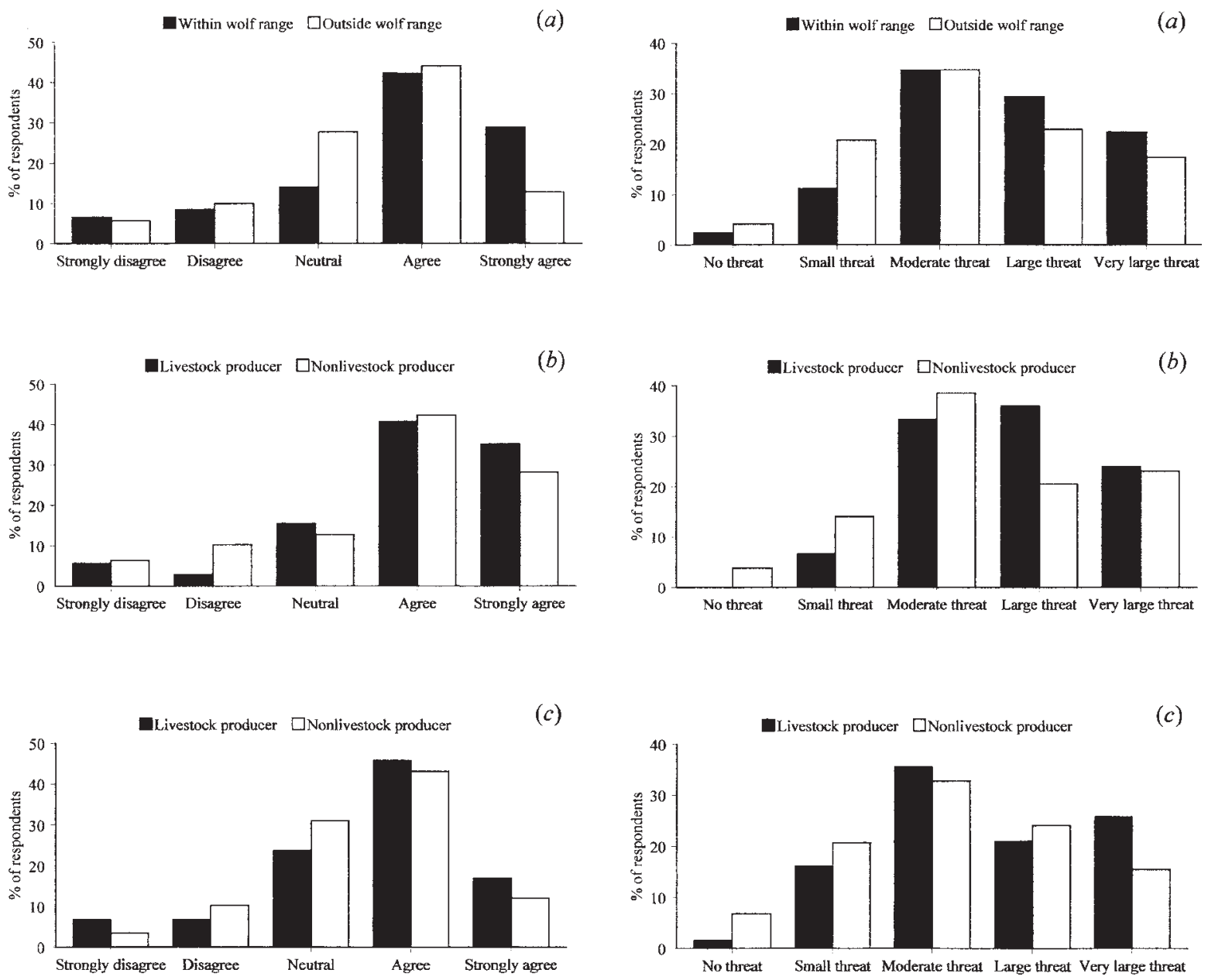

Figure 3. Distribution of responses to "Timber wolves are causing unacceptable levels of damage to northwest Minnesota's livestock industry" for rural residents in northwest Minnesota, 1999, within and outside wolf range (a), between livestock and nonlivestock producers within wolf range (b), and between livestock and nonlivestock producers outside wolf range (c).

$3.28 \pm 1.11, n=144 ; t=2.465, \mathrm{df}=312, P=0.014)$, even though the "no wolf group" also felt wolves presented a moderate to large threat to farming. When we examined the distribution of respondents in both geographic groups, we found that $51.8 \%$ of respondents in the "wolf group" perceived wolves as either a large or very large threat to farming, while $40.3 \%$ of the "no wolf group" perceived wolves as either a large or very large threat (Figure $\left.4 a ; \mathrm{c}^{2}=7.68, \mathrm{df}=4, P=0.104\right)$. Livestock producers within the "wolf group" perceived wolves as a moderate to large threat to farming in northwest Minnesota $(\bar{x}=3.77 \pm 0.89, n=75)$, which was

Figure 4. Distribution of responses to "the level of threat that wolves pose to livestock in northwest Minnesota." for rural residents in northwest Minnesota, 1999, within and outside wolf range (a), between livestock and nonlivestock producers within wolf range (b), and between livestock and nonlivestock producers outside wolf range (c).

slightly higher than the nonlivestock producer group $(\bar{x}=3.45 \pm 1.11, n=78 ; t=1.985, \mathrm{df}=151$, $P=0.049)$. We found that $60 \%$ of livestock producers perceived wolves as either a large or very large threat to farming compared to $43.6 \%$ of nonlivestock producers (Figure $4 b$ ). The relationship between occupation type and perceived level of threat wolves posed to farming in northwest Minnesota was not significant $\left(\chi^{2}=8.46, \mathrm{df}=4, P\right.$ $\left.=0.076, \tau_{c}=-0.167\right)$.

Within the "no wolf group" both occupation types perceived wolves as a moderate to large threat to farming in northwest Minnesota (livestock 
Table 3. Perceived threats to farming in northwestern Minnesota ranked from least to greatest threat by mean Likert score ( $1=$ no threat, $5=$ very large threat).

\begin{tabular}{|c|c|c|c|c|c|}
\hline \multicolumn{3}{|l|}{ Within wolf range } & \multicolumn{3}{|l|}{ Outside wolf range } \\
\hline Threat & $\bar{x}$ & $(\mathrm{SD})$ & Threat & $\bar{x}$ & (SD) \\
\hline Livestock diseases & 3.07 & $(1.87)$ & Predators & 3.06 & $(1.54)$ \\
\hline Crop pests & 3.30 & $(1.40)$ & Livestock diseases & 3.09 & $(1.92)$ \\
\hline Predators & 3.32 & $(1.37)$ & Flooding & 3.45 & $(1.53)$ \\
\hline Flooding & 3.59 & $(1.41)$ & Crop pests & 3.51 & $(1.48)$ \\
\hline Extreme weather conditions & 3.81 & $(1.25)$ & Extreme weather conditions & 3.99 & $(1.37)$ \\
\hline Crop diseases & 3.96 & $(1.31)$ & Laws/Government & 4.00 & $(1.75)$ \\
\hline Laws/Government & 4.21 & $(1.54)$ & Crop diseases & 4.14 & $(1.48)$ \\
\hline Market fluctuations & 4.57 & (1.08) & Market Fluctuations & 4.66 & $(1.31)$ \\
\hline
\end{tabular}

birds (family Icteridae), geese and ducks (family Anatidae), and wolves (Table 4). Ranked within the "no wolf group", perceived threats were sandhill cranes, bobcats, geese and ducks, other birds, deer, moose, bears, domestic dogs, coyotes, blackbirds, and wolves.

\section{Discussion}

producers: $\bar{x}=3.53 \pm 1.10, n=62$; nonlivestock producers: $\overline{\mathrm{x}}=3.21 \pm 1.15, n=58 ; t=1.585$, $\mathrm{df}=118$, $P=0.116)$. In the livestock producer group, $46.8 \%$ of the respondents perceived wolves as either a large or very large threat to farming in northwest Minnesota, while $39.6 \%$ of the respondents in the nonlivestock producer group perceived wolves as either a large or very large threat (Figure $4 c ; \chi^{2}=$ 4.07 , df $\left.=4, P=0.397, \tau_{\mathrm{c}}=0.148\right)$.

\section{Order of various perceived threats to farming}

Ranked from least to greatest by mean score, perceived threats to farming in northwest Minnesota in the "wolf group" included livestock diseases, crop pests, predators, flooding, extreme weather conditions, crop diseases, laws and government, and market fluctuations (Table 3). Respondents in the "wolf group" felt all threats ranged between moderate and very large. Ranked from least to greatest by mean scores, perceived threats to farming in the "no wolf group" were predators, livestock diseases, flooding, crop pests, extreme weather conditions, laws and government, crop diseases, and market fluctuations. Respondents in the "no wolf group" also felt that all of the threats ranged between moderate and very large.

\section{Comparison of perceptions regarding various wildlife species' threats to farming}

Ranked within the "wolf group" from least to most by mean score, perceived threats various wildlife species posed to farming in northwest Minnesota included bobcats (Lynx rufus), bears (Ursus americanus), deer (Odocoileus virginianus), moose (Alces alces), domestic dogs, birds, coyotes ( $C$. latrans), sandhill cranes (Grus canadensis), black-
Respondents in our survey were mostly older males with a predominantly rural agricultural background. Residents of many sampled households openly admitted during delivery of the survey that they would defer the questionnaire to the "man of the house", even when the woman was supposed to respond to the survey, because men were the major decision-makers with regard to agricultural practices. Most respondents were involved in agriculture and livestock production. Persons with such characteristics are likely to express relatively conservative attitudes toward a variety of environmental issues, including the presence of wolves in northwest Minnesota (Van Liere and Dunlap 1980; Kellert 1986, 1996, 1999).

Respondents in both groups revealed slightly unfavorable attitudes toward wolves. When asked whether "wolves should be allowed to exist in northwestern Minnesota" both groups were between neutral and disagree. Even when the stipulation "if wolves do not disturb livestock often" was added to the above question, both groups still had mean response scores between neutral and disagree. Interestingly, the stipulation made respondents more polarized about the question, with fewer respondents selecting the neutral response choice. However, Kellert (1999) documented an increase in positive attitudes toward wolves among farmers in Minnesota from 1985 to 1998.

These attitudes were consistent with respondents' perceptions that wolves posed a risk to livestock and farming in northwest Minnesota. A majority of respondents in both groups agreed or strongly agreed that wolves were causing unacceptable levels of damage to northwestern Minnesota's livestock industry. Furthermore, of all wildlife species listed, wolves were perceived as the greatest threat to farming, even for respondents in the "no wolf group" that 
Table 4. Perceived threats from wildlife to farming ranked from least to greatest threat by mean Likert score $(1=$ no threat, $5=$ very large threat $)$ in northwestern Minnesota within and outside of wolf range.

\begin{tabular}{|c|c|c|c|c|c|}
\hline \multicolumn{3}{|c|}{ Within wolf range } & \multicolumn{3}{|c|}{ Outside wolf range } \\
\hline Species & $\bar{x}$ & (SD) & Species & $\bar{x}$ & $(\mathrm{SD})$ \\
\hline Bobcat & 1.84 & $(1.64)$ & Sandhill crane & 1.57 & (1.36) \\
\hline Bears & 2.11 & $(1.37)$ & Bobcat & 1.87 & $(1.54)$ \\
\hline White-tailed deer & 2.11 & $(1.52)$ & Geese and ducks & 1.89 & $(1.44)$ \\
\hline Moose & 2.13 & $(1.80)$ & Other birds & 1.94 & (2.05) \\
\hline Domestic dog & 2.40 & $(1.50)$ & White-tailed deer & 2.10 & (1.40) \\
\hline Other birds & 2.55 & $(2.44)$ & Moose & 2.18 & (1.43) \\
\hline Coyote & 2.70 & $(1.87)$ & Bears & 2.36 & $(1.57)$ \\
\hline Sandhill crane & 2.79 & $(1.79)$ & Domestic dog & 2.46 & (1.63) \\
\hline Blackbirds & 3.06 & $(1.56)$ & Coyote & 2.48 & $(1.71)$ \\
\hline Geese and ducks & 3.15 & $(1.47)$ & Blackbirds & 2.49 & $(1.47)$ \\
\hline Timber wolves & 3.71 & $(1.30)$ & Timber wolves & 3.43 & $(1.41)$ \\
\hline
\end{tabular}

pendent of personal experience." However, other proximate factors related to direct personal experiences (e.g., the threat that wolves pose to pets, competition with wolves for big game, and tight restrictions on managing wolves) may need investigation before this claim is made with complete certainty.

It is possible that cultural biases may play an important role in shaping rural perceptions toward wolves in northwest Minnesota because of strong-

had not lived within wolf range for nearly 100 years.

We found significant differences in the perception of risk that wolves posed to livestock between respondents in the geographic groups but not between occupations. Although these differences were statistically different, the differences were minor considering the mean scores were not substantively different and there was no association between geographic group and the level of agreement with the statement "Wolves are causing unacceptable levels of damage to northwest Minnesota's livestock industry." Differences between livestock and nonlivestock producers in either group were expected since livestock producers have the potential to be more economically impacted by wolves. Other studies also have found that farmers and ranchers hold the strongest beliefs against wolves (Kellert 1986, Nelson and Franson 1988, Bath and Buchanan 1989).

Lack of major differences in attitude and perception between geographic groups and occupations suggests that proximate factors have little influence on rural residents' attitudes and perceptions toward wolves in northwest Minnesota. This was surprising since residents within wolf range and residents involved with livestock production reported more negative experiences with wolf depredations on livestock than residents outside of wolf range and residents not involved with livestock production. This observation was consistent with Kellert et al.'s (1996: 980) assertion "these results and other studies consistently reveal deeply ingrained biases among agriculturists, particularly livestock producers, against wolves and other large predators, often inde- ly shared cultural beliefs, norms, and values generally found in rural communities. Since many rural occupations are nature-extractive, rural residents often hold utilitarian attitudes toward the natural environment (Tremblay and Dunlap 1978, Kellert 1986). Wolves may lack value for many rural residents with respect to the rural lifestyle. Utilitarian attitudes toward the natural environment may spread throughout the rural community, even to those not involved in farming, through various mechanisms not based on economics but on the shared nostalgia of rural lifestyles (Salamon 1989). For instance, attitudes that preserve remnant traits of an area's founding and settling pattern generally are highly regarded in the community. Wolves have a long negative history in rural communities, particularly among communities with immigrant roots in Europe because of their negative portrayal in popular European folklore and early conflicts between wolves and livestock producers (Fogleman 1988, Fritts et al. 2003). Because both geographic groups shared similar attitudes and perspectives toward wolves, we speculate that cultural biases played a role in shaping rural attitudes toward wolves in northwest Minnesota. Such biases likely had more influence than proximate factors related to direct personal experience.

The lack of substantial differences between geographic and occupational groups also may be related to the perception that predators were less of a threat to agriculture in northwest Minnesota than other agricultural threats. Within the "wolf group", predators ranked behind market fluctuations, laws and the government, crop disease, extreme weath- 
er conditions, and flooding in regard to their level of perceived threat to farming. Within the "no wolf group", predators ranked last behind all other threats mentioned. Hence, predator issues, like wolf-livestock conflicts, may not have caused great enough concern among rural residents to create divisions in their attitudes and perspectives toward wolves. This lack of concern over the threat of predators to farming was corroborated by the low percentage $(37 \%)$ of livestock producers residing within wolf range practicing some method of livestock protection and the relative ineffectiveness of the top 4 methods used by producers to protect livestock from wolves.

Our findings are consistent with rural attitudes toward wolves in other parts of North America where wolf populations exist or where wolf reintroduction has been proposed (e.g., Kellert 1986; Bath 1987, 1991; Biggs 1988; Tucker and Pletcher 1989). Lack of major differences between rural respondents by geographic group or occupation suggests that no matter what risk wolves pose to livestock, rural perceptions toward wolves in northwest Minnesota will remain negative due to strong cultural anti-wolf biases. The negative social stigma wolves have garnered for centuries (Kellert 1986, Fritts et al. 2003) may well be the most important factor influencing rural attitudes toward wolves in northwestern Minnesota.

\section{Management implications}

Although wolves did not kill large quantities of livestock annually $(<1 \%$ of all the livestock in the study area, Chavez 2002), rural residents in northwest Minnesota were not favorable to the existence of wolves in the area. However, completely remov-

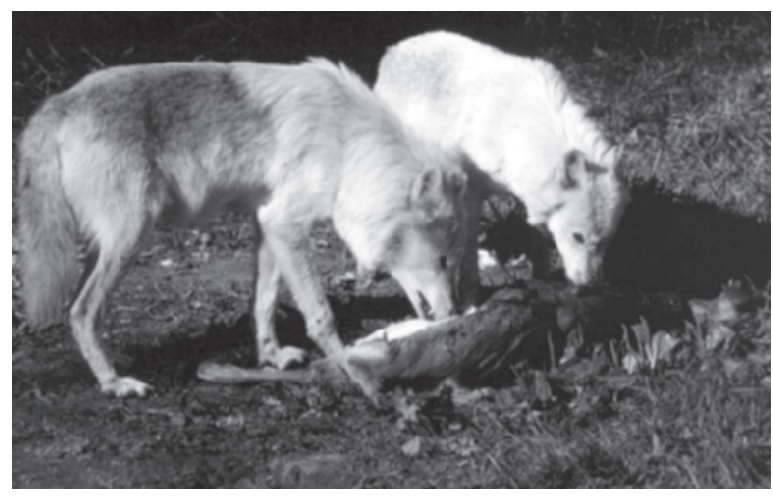

Wolves are a controversial species and viewed as a threat to livestock by rural landowners in Minnesota.

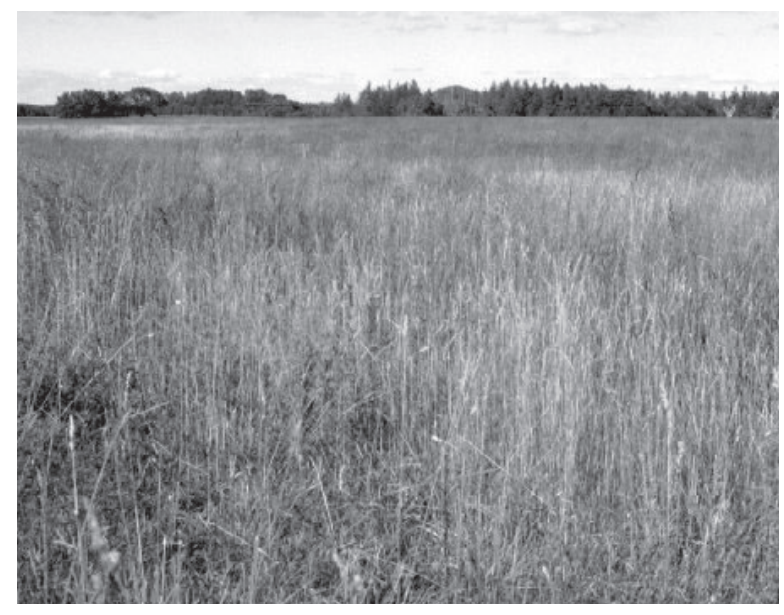

The interface between agricultural lands and woodlands in Minnesota puts wolves and livestock in close proximity.

ing wolves is unlikely given current legal wolf control techniques (Mech 2000) and because wolves can quickly repopulate vacant territories (Chavez 2002). We found little difference in attitude toward wolves between residents living in close proximity to wolves and those living outside wolf range and between residents who did and did not raise livestock. Any efforts for public education about wolf recovery and management would need to concentrate on the entire rural resident population in northwest Minnesota, rather than on just those directly affected by wolves (Mech 1995). We also suggest further research on rural attitudes toward wolves to examine the role of cultural and social biases in shaping attitudes and perceptions.

Acknowledgments. Logistical and financial support was provided by the United States Fish and Wildlife Service's Agassiz National Wildlife Refuge, Middle River, Minnesota, and the United States Department of Agriculture's Wildlife Services, National Wildlife Research Center, Logan Field Station at Utah State University, Logan, Utah. We thank M. Young, K. Frykmen, M. Hackett, C. Hill, E. Peacock, S. Naftal, A. Hendel, J. Sikich, S. Richter, S. Graham, M. Clark, R. Callan, E. Joyce, L. Schutte, J. Muntifering, and E. Bergman for their dedicated field assistance; and M. Anderson, G. Huschle, S. Wockenfuss, D. Van Eps, and the rest of the staff at Agassiz National Wildlife Refuge for logistical assistance. M.Anderson, B. Gilbert, and G. Huschle provided reviews of earlier drafts of the manuscript. Research protocols were approved by the Institutional Animal Care and Use Committee (\#879) and 
the Institutional Review Board (for research involving human subjects) at Utah State University.

\section{Literature cited}

BABBIE, E. 1990. Survey research methods. Wadsworth, Belmont, California, USA.

BATH,A. J. 1987.Attitudes of various interests groups in Wyoming toward wolf reintroduction in Yellowstone National Park. Thesis, University of Wyoming, Laramie, USA.

BAтH,A. J. 1991. Pubic attitudes in Wyoming, Montana, and Idaho toward wolf restoration in Yellowstone National Park. Transactions of the North American Wildlife and Natural Resource Conference 56:91-95.

Bath, A. J., and T. BuChanan. 1989. Attitudes of interest groups in Wyoming toward wolf restoration in Yellowstone National Park. Wildlife Society Bulletin 17:519-525.

BERG, W. E., AND S. BENSON. 1999. Updated wolf population estimate for Minnesota, 1997-1998. Minnesota Department of Natural Resources, Grand Rapids, USA.

BIGGS, J. R. 1988. Reintroduction of the Mexican wolf into New Mexico: an attitude survey. Thesis, New Mexico State University, Las Cruces, USA.

ChaveZ, A. S. 2002. Assessing the potential, actual, and perceived risk that gray wolves, Canis lupus, pose to livestock in northwestern Minnesota.Thesis, Utah State University, Logan, USA.

Dillman, D.A. 1978. Mail and telephone surveys: the total design method. Wiley and Sons, New York, New York, USA.

Fogleman, V. M. 1988. American attitudes towards wolves: a history of misperception. Environmental Ethics 10: 63-94.

FRITTS, S. H. 1982. Wolf depredation on livestock in Minnesota. United States Department of the Interior, Fish and Wildlife Service Resource Publication 145, Washington, D.C., USA.

FRITTS, S. H., AND L. D. MECH. 1981. Dynamics, movements, and feeding ecology of a newly protected wolf population in northwestern Minnesota. Wildlife Monographs 80.

FritTs, S. H., W. J. PAuL, L. D. MeCh, AND D. P. SCOTT. 1992.Trends and management of wolf-livestock conflicts in Minnesota. United States Department of the Interior, Fish and Wildlife Service Resource Publication 181, Washington, D.C., USA.

Fritts, S. H., R. O. StePhenson, R. D. Hayes, ANd L. Boitani. 2003. Wolves and humans. Pages 289-316 in L. D. Mech, and L. Boitani, editors. Wolves: behavior, ecology, and conservation. University of Chicago Press, Chicago, Illinois, USA.

Fuller, T. K., W. E. BerG, G. L. RAdDE, M. S. LeNARZ, AND G. B. Joselyn. 1992. A history and current estimate of wolf distribution and numbers in Minnesota. Wildlife Society Bulletin 20: 42-55.

KeLLERT, S. R. 1986. The public and the timber wolf in Minnesota. Transactions of the North American Wildlife and Natural Resource Conference 51: 193-200.

Kellert, S. R. 1996. The value of life: biological diversity and human society. Island Press, Washington, D.C., USA.

KeLLeRT, S. R. 1999.The public and the wolf in Minnesota. Report to the International Wolf Center, Minneapolis, Minnesota, USA.

Kellert, S. R., M. Black, C. R. Rush, and A. J. Bath. 1996. Human culture and large carnivore conservation in North America. Conservation Biology 10: 977-990.

Kuinghammer, E. 1989. The wolf: fact and fiction. Pages 77-91 in R. J. Hoage, editor. Perceptions of animals in American culture. Smithsonian Institution Press, Washington D.C., USA.

LopeZ, B. H. 1978. Of wolves and men. Scribner's Sons, New York,
New York, USA

MCNaught, D. A. 1987. Wolves in Yellowstone?-Park visitors respond. Wildlife Society Bulletin 15:518-521.

MeCH, L. D. 1995. The challenge and opportunity of recovering wolf populations. Conservation Biology 9: 1-9.

MECH, L. D. 1998. Estimated costs of maintaining a recovered wolf population in agricultural regions of Minnesota. Wildlife Society Bulletin 26: 817-822.

MeCH, L. D. 2000. The wolves of Minnesota: howl in the heartland. Voyageur Press, Stillwater, Minnesota, USA.

Nelson, E., and C. Franson. 1988. Timber wolf recovery in Wisconsin: the attitudes of northern Wisconsin farmers and landowners. Research Management Findings 13, Wisconsin Department of Natural Resources, Madison, USA.

Pate, J., M. J. Manfredo, A. D. Bright, and G. Tischbein. 1996. Coloradans' attitudes toward reintroducing the gray wolf into Colorado. Wildlife Society Bulletin 24: 421-428.

PAuL, W. J. 1999. Wolf depredation of livestock in Minnesota annual update of statistics - 1998. United States Department of Agriculture, Animal Plant Health and Inspection Service, Wildlife Services, Grand Rapids, Minnesota, USA

REAM, R. R. 2000. Minnesota wolf range: past, present, and future. Pages 28-35 in L. D. Mech, editor.The wolves of Minnesota:howl in the heartland. Voyageur Press, Stillwater, Minnesota, USA.

SAlamon, S. 1989. What makes rural communities tick? Rural Development Perspectives. United States Department of Agriculture, Economic Research Service, Washington, D.C., USA.

SPSS. 1998. SPSS for Windows, Release 9.0. SPSS Inc., Chicago, Illinois, USA.

TREMBley., K. R., JR., AND R. E. DunLaP. 1978. Rural-urban residence and concern with environmental quality: a replication and extension. Rural Sociology 43: 474-491.

TuCKer, P., AND D. Pletcher. 1989. Attitudes of hunters and residents toward wolves in northwestern Montana. Wildlife Society Bulletin 17: 509-514.

United States Fish and Wild Life Service. 1992. Recovery plan for the eastern timber wolf. Eastern Timber Wolf Recovery Team, United States Fish and Wildlife Service, Washington, D.C., USA.

VAN LIERE, K. D., AND R. E. Dunlap. 1980. The social bases of environmental concern: a review of hypotheses, explanations and empirical evidence. Public Opinion Quarterly 44: 181-197.

VAUGHAN, E. 1990. Some factors influencing the nonexpert's perception and evaluation of environmental risks. Garland Publishing, New York, New York, USA.

Andreas S. Chavez (photo) is currently a wildlife biologist with the United States Fish and Wildlife Service in Carlsbad, California. He received his B.A. degree in biology at University of Califor-nia, Berkeley and his M.S. degree in wildlife ecology at Utah State University. His research and management interests include carnivore ecology and management and conservation of mammals. Eric M. Gese is a research wildlife biologist with the National Wildlife Research Center and a research

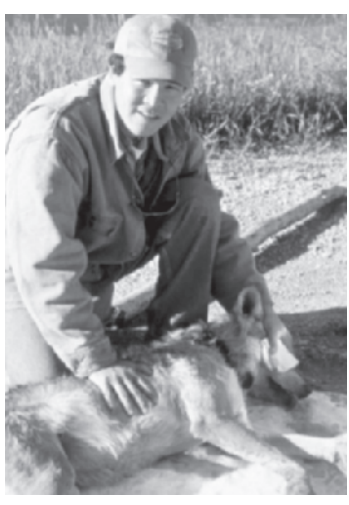
associate professor in the Department of Forest, Range, and Wildlife Sciences at Utah State University. Eric received his 
B.S. in biology from the University of Texas at San Antonio, and his M.S. and Ph.D. in wildlife ecology from the University of Wisconsin at Madison. For the past 21 years his research interests have included predator_prey relationships, predator_predator interactions, and behavior, ecology, and management of carnivores. Current activities include research projects on swift foxes, coyotes, wolves, mule deer, pronghorn, and jaguars. Richard S. Krannich is professor and head of the Department of Sociology, Social Work and Anthropology at Utah State University. He received his Ph.D. in sociology from Pennsylvania State University. His research focuses on the social implications of natural resource use, development and management, with a primary emphasis on resource and environmental issues affecting nonmetropolitan areas of the Intermountain West. Currently he is engaged in research focusing on rural community response to hazardous and nuclear waste facility siting, social values and public preferences regarding wildlife resource management, and the implications of changes in resource-based economies for social organization and social well-being in western rural communities.

Associate editor: Whittaker 